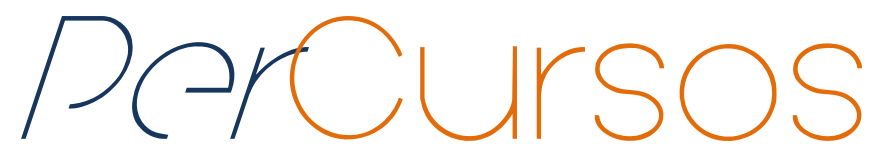

\title{
Direitos socioambientais, conservação neoliberal da natureza e agricultores no Parque Estadual da Pedra Branca, RJ
}

\begin{abstract}
Resumo
Baseado na análise da ocupação histórica de agricultores familiares (descendentes de carvoeiros e quilombolas) que habitam áreas transformadas no Parque Estadual da Pedra Branca (PESPB), uma UC de proteção integral situada na Zona Oeste da Cidade do Rio de Janeiro, o artigo discute o papel que a combinação de discursos ambientais, políticas/legislação e mercados "verdes" têm no avanço do fenômeno da apropriação de terras para fins de conservação ambiental (green grabbing). Argumenta-se que a crescente modificação de terras tradicionalmente ocupadas, em territórios para turistas, no Brasil, seja parte de uma agenda global de proteção da natureza, na qual habitantes de áreas com interesse para conservação da natureza devam ser retirados ou permanecer em estado pré-moderno idílico , cristalizados e, portanto, em grande medida afastados dos benefícios da modernidade, com a finalidade de permanecerem sendo os guardiões da natureza e apenas coadjuvantes no crescente e multibilionário mercado de turismo ecológico e étnico. O artigo desenvolve a tese de que o fenômeno do green grabbing em paralelo aos mecanismos de formação de territórios para turistas é propagado, ao menos em parte, por meio do que pode ser denominado de mais-valia socioambiental. Por fim, é apresentada uma análise preliminar que busca integrar perspectivas geográficas, antropológicas e do Direito, afim de contribuir no entendimento desses complexos fenômenos e, acima de tudo, promover a defesa de direitos fundamentais, como o direito pré-existente de moradia e acesso aos recursos naturais para todos, a que se faz jus um grupo historicamente marginalizado.
\end{abstract}

Palavras-chave: Conservação neoliberal. Comunidades tradicionais. Carvoeiros. Quilombolas. Agricultores familiares.

\author{
Rodrigo Penna-Firme \\ Doutor em Antropologia pela \\ Indiana University, Estados \\ Unidos. Professor da Pontifícia \\ Universidade Católica do Rio de \\ Janeiro - PUC-RIO. \\ Brasil \\ rodrigopennafirme@puc-rio.br
}

\footnotetext{
Para citar este artigo:

PENNA-FIRME, Rodrigo. Direitos socioambientais, conservação neoliberal da natureza e agricultores no Parque Estadual da Pedra Branca, RJ. Revista PerCursos, Florianópolis, v. 19, n.39, p. 50 - 76, jan./abr. 2018.
}

DOI: 10.5965/1984724619392018050

http://dx.doi.org/10.5965/1984724619392018050 


\title{
Socio-environmental rights, neoliberal conservation and smallholders in the Pedra Branca State Park, RJ
}

\begin{abstract}
Based on a historical analysis of a smallholder community's occupation (descendants of charcoal workers and quilombolas) in an area recently turned into a State Park, situated in the West Zone of the city of Rio de Janeiro, the article discusses the role environmental discourses, policies/legislation and "green" markets may have in advancing green grabbing - the phenomenon of the land appropriation for environmental conservation. It is argued that the transformation of many traditionally occupied territories into tourist territories, in Brazil, is part of a global agenda aimed at nature protection, through which inhabitants of high biodiversity areas should be removed or stay in a pre-modern, idyllic and crystallized state, and therefore, remain alienated from the benefits of modernity, in order to serve as nature stewards while supporting the growing, multibilliondollar ecological and ethnic tourism market. The article also argues that the phenomenon of green grabbing along with the formation of territories for tourists is propagated, at least in part, through what can be called socio-environmental surplus value. Finally, a preliminary analysis is provided as a way to integrate geographic, anthropological and legal perspectives, in order to contribute to understanding such complex phenomena and, above all, to promote the defense of fundamental rights, such as the preexisting rights of housing and access to natural resources for all, to which a historically marginalized group is entitled.
\end{abstract}

Keywords: Neoliberal Conservation. Traditional communities. Charcoal people. Quilombolas. Smallholders 


\section{Introdução}

A crescente mercantilização das relações entre natureza e sociedade e da natureza em si mesma vem se tornando estratégia central no avanço do capitalismo moderno (PORTO-GONÇALVES, 2006), que aqui denominamos de capitalismo verde. No nosso entendimento, uma das características mais marcantes dessa nova fase do capitalismo global é uma combinação intensa, ou melhor, uma aproximação perigosa de dependência entre este processo e os novos discursos da sustentabilidade. Tais discursos, por sua vez, produzem e são produtos das transformações do espaço via força de mercado (impulsionados pela cultura do consumo), pelo cientismo ou cientificismo (HACOHEN, 2000)- percepção da ciência como uma espécie de religião global e secular, e cujo papel é ser a fonte de todas as respostas práticas, e também dos mais profundos anseios humanos e, finalmente, não menos importante, do aparato midiático que globaliza desejos de consumo, ao forjar identidades e padrões de comportamento que sirvam de modelos civilizatórios estruturantes de uma nova ordem mundial (póscolonial), que reorganize a divisão do trabalho e do acesso aos recursos naturais entre povos e nações, desenvolvidos e em desenvolvimento.

Apesar das forças que buscam homogeneizar sociedades, economias e culturas, é inegável que existam efeitos colaterais inesperados. Mobilizações sociais têm surgido explicitamente contrárias ao processo de globalização e o acompanhante fenômeno de mercantilização da natureza e das culturas. Exemplos emblemáticos desse tipo de resistência são os protestos contra a privatização da água na Bolívia (OLIVERA, 2004) e as reinvindicações de povos indígenas americanos pela repatriação de objetos de valor simbólico e histórico de sua cultura, atualmente enclausurados e mercantilizados em museus Europeus e Norte Americanos (JENKINS, 2010).

Pelo mundo, também vem se tornando cada vez mais comuns os movimentos que visam o resgate de tradições culturais à beira da extinção. É interessante notar que apesar das consequências negativas do avanço desigual dos benefícios trazidos pela modernidade, é o próprio contato cultural acelerado, produzido no bojo do capitalismo moderno, que tem provocado invenções, renovações, e resgates culturais, na medida em 
que o encontro entre cosmologias locais e globais produz alteridade, ou seja, provoca o refletir sobre si mesmo a partir do olhar lançado sobre o outro, sobre o diferente. É por meio do encontro de forças desiguais, que grupos marginalizados se sentem compelidos, apoiados e até mesmo pressionados a lutar pela criação, ampliação e reconhecimento de novos direitos socioambientais, como o direito de permanência em terras tradicionalmente ocupadas (ALMEIDA, 2012), assim como o direito de compartilhar dos benefícios econômicos associados à biodiversidade e aos conhecimentos tradicionais associados seu uso e manejo (CUNHA, 2009). Entendemos que a globalização da lógica de mercado, o capitalismo neoliberal em si, nutre-se das suas próprias contradições, e não pode superá-las, mas apenas mascará-las temporariamente.

Ao transformarmos a natureza em conjunto de objetos e serviços na "prateleira" de um mercado de consumo global, criamos uma série de possiblidades e restrições para grupos humanos específicos. Em primeiro lugar, o acesso aos bens naturais e suas provisões torna-se gradativamente privilégio daqueles indivíduos, instituições, governos e corporações financeiramente capazes de pagar por isso. Também, na medida em que os recursos naturais tornam-se mais escassos, com a manutenção ou aumento da demanda, seu valor de mercado tenderá ao crescimento, favorecendo, prioritariamente, as elites econômicas mundiais e nacionais que controlam cada vez mais a produção, o manejo, a comercialização e o consumo desses bens e serviços.

Em segundo lugar, por restringirmos os valores de uso, e enaltecermos os valores de troca, alteramos adversamente a reprodução cultural e material de milhões de pessoas que ainda vivem, quase que exclusivamente, fora das relações de mercado. Ou seja, são pessoas e unidades familiares que dependem diariamente da provisão gratuita da natureza para sobreviver, seja através da obtenção de lenha para cozinhar, da coleta de plantas medicinais, do acesso às fontes de água potável, da caça e da pesca, dentre outros. Na medida em que o acesso aos recursos naturais tem sido a cada dia restringido por meio de mecanismos de mercado, ou seja, pela lógica da compra e da venda, da demanda e da oferta, milhões de pessoas por todo o mundo tem perdido o direito de acesso a esses recursos, assim como, o conhecimento tradicional de como usá-los tem sido erodido. Será que no Brasil, por exemplo, a transferência de renda para os mais 
pobres, com o objetivo de trazer milhares de famílias da pobreza para o mercado de consumo, apesar de gerar benefícios, não geraria mais riscos e dependência no longo prazo para a sobrevivência dessas mesmas famílias hoje beneficiadas? Será que, supostamente, diminuir a dependência que essas pessoas têm dos recursos naturais locais, colocando-as marginalmente em mercados de consumo seria a solução para mudar as estruturas e raízes históricas que produziram essas discrepâncias socioeconômicas? Está amplamente demonstrado na literatura internacional, que ao contrário do que pode parecer o "senso econômico comum", que supõem que indivíduos mesmo em grupos/comunidades agirão de modo a maximizar benefícios privados às custas do desenvolvimento coletivo, comunidades locais no mundo todo têm desenvolvido regras (instituições) capazes de lidar com dilemas de uso comum dos recursos naturais, de forma sustentável, sem no entanto, depender exclusivamente de forças mercadológicas externas (OSTROM, 2007).

Nessa perspectiva, a globalização da natureza (PORTO-GONÇALVES, 2006, op. cit.) também pode ser interpretada como intencionalidade do capital global para restringir o uso e o acesso de recursos naturais finitos a certos grupos em detrimento de outros, a certos países em detrimento de outros, e assim por diante. A resposta que muitos de nós ofereceríamos para duas perguntas simples indica que a questão do controle dos recursos naturais por elites nacionais e internacionais, via mercados globais, não é mais uma inócua teoria de conspiração global, muito pelo contrário, nos parece realidade inexorável. Vejamos: qual o perfil socioeconômico das pessoas que usufruem das delícias naturais de Cancun e Fernando de Noronha? Quem pode degustar as últimas lagostas e atuns em extinção dos oceanos?

No balanço geral, com os mínimos avanços no processo de demarcação de terras indígenas e quilombolas, ou de reforma agrária mais amplamente, o que temos testemunhado é a contínua transferência do uso e controle dos recursos naturais dos pobres, dos camponeses, dos indígenas, dos povos e comunidades tradicionais para fazendeiros de soja e gado, para o estabelecimento de UCs, para a construção de usinas hidroelétricas e assim por diante. Novos conflitos socioambientais surgirão com a 
ampliação de "negócios sustentáveis", como os reflorestamentos voltados para a captura de carbono, as plantações de biocombustível, os parques eólicos, dentre outros.

Por fim, a "novidade" no avanço do capitalismo contemporâneo é de grau e não de tipo. Ela reside, dentre outros aspectos, principalmente, na dependência do desenvolvimento econômico segundo uma visão de sustentabilidade global. Essa, por sua vez, tem sido ampliada como justificativa de uma agenda global de controle dos recursos naturais por parte de países desenvolvidos. Não podemos negar uma série de mudanças positivas que têm sido impulsionadas pelo novo paradigma ecológico que afeta, por exemplo, processos produtivos industriais e agrícolas. Reduzir o uso de agrotóxicos, economizar água, reciclar diversos materiais, e tantas outras iniciativas, é inegavelmente fundamental.

O que vimos argumentando é que tais avanços não podem, por si só, superar as contradições inerentes ao sistema econômico atual que se globaliza a passos largos. $O$ cenário mais amplo nos conforta, à primeira vista, pois temos a impressão de que transitamos de um capitalismo selvagem, cujo céu cinzento simbolizava o progresso, e caminhamos para outro menos voraz, com o céu mais azul e os campos mais verdes. Essa é uma verdade parcial. Acreditamos, assim como Zizek (2016), que a ecologia vem se tornando a nova utopia global após o fracasso do comunismo e de algumas formas de socialismo pelo mundo. A ecologia como ideologia societária, como base filosófica de diversas práticas também atua como uma espécie de substituto, ou melhor, como se abrisse ao mundo, aos indivíduos, uma segunda oportunidade de corrigir os erros da humanidade, de finalmente atingirmos, como coletividade, as promessas não cumpridas pela modernidade, que incluem um mundo mais justo, mais confortável, mais seguro e feliz para todos, ou quase todos. O discurso da sustentabilidade global, que nasce de reformulações políticas, de interesses econômicos e da popularização de perspectivas da ciência ecológica moderna, apesar de seus reais e potenciais benefícios, nos parece, um novo e poderoso ópio do povo. Para ZHOURI (2008), a sustentabilidade de uma sociedade como a brasileira, diversa e extremamente desigual, necessita de equacionamento que considere a centralidade da diversidade cultural, e a 
democratização do acesso aos recursos naturais, o que, ao nosso ver, é princípio não negociável de justiça ambiental (ACSELRAD. 2010).

\section{Conservação Neoliberal e Green Grabbing}

Por décadas, a questão da apropriação e distribuição desigual dos recursos naturais tem sido o foco de análises da geografia e de disciplinas correlatas, como a antropologia ambiental e a ecologia política. No entanto, apenas mais recentemente, no cruzamento dessas disciplinas, o termo green grabbing foi elaborado, e, desde então, tem sido utilizado para designar formas particulares de controle e a apropriação da natureza. Essa expressão poderia ser traduzida como apropriação "verde" de territórios e recursos naturais. Em outras palavras, o termo refere-se a todo e qualquer processo de apropriação de territórios para fins ambientais e para a promoção do desenvolvimento sustentável. Ou seja, é o processo pelo qual "credenciais verdes" e discursos sobre desenvolvimento são utilizados para justificar a apropriação de terras para alimentos, biocombustíveis, sequestro de carbono, conservação da natureza e ecoturismo (FAIRHEAD, LEACH, SCOONES 2013).

A criação de UCs para fins de conservação e turismo pode ser entendida como um tipo específico de green grabbing (FLETCHER, DRESSLER, BUSCHER, 2014). Tanto a tomada de terras para produção de biocombustíveis, como a delimitação de territórios para conservação seguem a mesma lógica, que como já mencionamos, tem sido denominado de conservação neoliberal, neoliberalização da natureza, ou mercantilização da natureza. Alguns analistas têm chamado de neocolonialismo o processo de criação de grande número de áreas protegidas - com ajuda técnico-financeira de países desenvolvidos, com vistas ao desenvolvimento do turismo e da proteção integral da natureza em países em desenvolvimento (BROCKINGTON, DUFFY, IGOE, 2010).

Ao mesmo tempo em que as áreas dentro e imediatamente fora das UCs tem se tornado territórios para turistas, um efeito ainda pouco estudado é a tendência de terras no entorno de áreas protegidas aumentarem seu valor de mercado. Em outros casos, áreas protegidas têm sido estabelecidas como estratégia para 'compensar' danos ao 
meio ambiente, como projetos de expansão da agricultura e industrial, de infraestrutura e mineração (BROCKINGTON DUFFY, IGOE, op. cit.). Na realidade essas compensações são fictícias, pois a área total voltada para fins de conservação aumenta relativa, e não absolutamente.

Entendemos que o termo neoliberalização da natureza, além de carregar em síntese a ideologia que busca transformar "tudo" em mercadoria/commodity, aponta para um conjunto de ações e discursos que vem sendo crescentemente usados por países, governos, instituições e indivíduos na formulação de políticas ambientais, especialmente, por meio da combinação de: (1) Transformação de conhecimentos técnico-científicos sobre o mundo natural, notadamente nos campos da ecologia e da biologia da conservação, em verdades absolutas, que servem de guias para a tomada de decisões políticas sobre o manejo de recursos naturais; (2) A ampliação de políticas econômicas que facilitam mecanismos de livre-mercado como justificativa para aumentar a eficiência e diminuir os custos de transação (também nas relações sociedade-natureza) o que inclui, mas não se limita, à descentralização do controle de territórios e a diminuição do papel do Estado nessas transações; (3) A ampla difusão do discurso de sustentabilidade através dos meios de comunicação em massa, acompanhada da transformação do discurso da sustentabilidade no "ópio do povo", conforme discutimos anteriormente quando apresentamos suscintamente algumas ideias do filósofo Slavoj Zizek.

Conforme argumentamos, a sustentação desse tipo de discurso baseia-se, dentre outras medidas, na criação e difusão do que estamos denominando de ecologia do medo. Essa é uma posição científico-filosófica que prega o catastrofismo ambiental irreversível, a não ser que medidas sustentáveis globais urgentes sejam tomadas conjuntamente por todos os povos da Terra. De acordo com essa perspectiva, o caminho de transição para uma sociedade planetária sustentável, encontra-se na adoção de medidas e princípios científico-ecológicos, e da adoção da economia de mercado, por meio, por exemplo, da implementação de pacotes tecnológicos “verdes" e, principalmente, pela valoração econômica da natureza, ou seja, de seus bens e serviços, entendidos em conjunto como capital natural. 
Notamos que em conjunto, tais medidas e discursos servem como justificativa para a ampliação de uma governança global sobre o uso dos recursos naturais do planeta; todo esse aparato visa criar, difundir, implantar e legitimar um conjunto de regras universais sobre como usar, quem pode usar, e a quando devemos usar a natureza. Essas regras de uma nova ordem socioambiental global buscam definir, em primeiro lugar, o que é natureza, quem tem o poder de dizer o que é essa natureza, e também quem tem o direito de se beneficiar com essa definição. Além da situação das UCs, já destacada, podemos citar outros exemplos emblemáticos da mercantilização da natureza e das relações cultura-natureza, como é o caso de reservas indígenas que comercializam créditos de carbono, incentivadas por multinacionais, das quais se tornam "parceiras comerciais".

Um caso revelador é a relação entre o Banco Mundial, comunidades rurais negras e o governo da Colômbia. Desde a década de 90, o banco tem financiando e apoiando, técnica e juridicamente, dezenas de processos que incluem desapropriações, demarcação de terras e a titulação definitiva de territórios tradicionais comuns de comunidades rurais negras (OFTEN, 2003). Mas qual seria o real interesse do banco em promover o reconhecimento étnico e a demarcação de territórios de comunidades negras e pobres localizadas no litoral pacífico daquele país? Em síntese, a resposta que o próprio autor nos fornece é que, algum tempo após a titulação, têm surgido parcerias entre empresas de biotecnologia e algumas dessas comunidades. Nesse sentido, garantir a titulação é uma importante quebra de barreira jurídica e econômica, de modo a possibilitar uma segurança jurídica para a entrada definitiva de investimentos estrangeiros (apenas com base no "consentimento" local) em uma região que ainda mantêm níveis altíssimos de biodiversidade e recursos minerais a serem explorados (ESCOBAR, PAULSON, 2005).

\section{A pobreza no paraíso ecológico e a mais valia socioambiental}

Apesar do aumento da conscientização sobre a existência de inúmeros conflitos entre moradores locais e unidades de conservação da natureza, pouco se sabe sobre os impactos negativos diretos que essas interações provocam na subsistência e reprodução 
cultural e material de populações rurais no Brasil e ao redor do mundo. Sabemos, por exemplo, que em países africanos como o Quênia, milhares de pessoas já foram literalmente expulsas de territórios historicamente habitados por seus ancestrais para dar lugar a diferentes tipos de unidades de conservação da natureza (BROCKINGTON, DUFFY, IGOE, 2010).

No Brasil, não sabemos quantas pessoas, casas, famílias ou mesmo comunidades já foram deslocadas, desapropriadas ou simplesmente expulsas para o estabelecimento de UCs. Assim como não existem estatísticas oficiais sobre quantas pessoas permaneceram por vontade própria, ou falta de opção, nas suas moradias e comunidades após a instalação de UCs no Brasil. No entanto, acreditamos que o processo de criação de UCs no Brasil tenha causado menos expulsões diretas (remoções, desapropriações) do que o número de UCs existentes pode sugerir. Isso não necessariamente diminui os impactos sociais causados por essas intervenções, mas apenas modifica-os qualitativamente. Especulamos duas razões primordiais para que haja um número maior de pessoas que permanecem dentro ou no entorno das UCs, do que o número de pessoas que foram expulsas. Primeiro, pelo menos no nível federal, existe um número maior de UCs de uso sustentável ou uso direto $(n=173)$ do que de UCs de proteção integral ou uso indireto ( $n=147)$ (ICMBio, 2016). Isso por si só evidencia, mais não prova que exista um maior número de residentes dentro de UCs do que o número de pessoas que habitavam essas áreas e foram desapropriadas.

Para entendermos melhor essa situação, vejamos com um pouco mais de cuidado o que descrevemos acima. Dentre a categoria de UCs de uso sustentável estão, por exemplo, as reservas extrativistas (RESEX), as reservas de desenvolvimento sustentável (RDS) e áreas de proteção ambiental (APA). Nessas, o objetivo é conciliar a conservação da natureza com a cultura local/tradicional e suas práticas de manejo. Entre as UCs de proteção integral destacamos os parques nacionais (PARNA) e as reservas biológicas (REBIO). Todos os PARNAs têm finalidade exclusiva de proteger os recursos naturais do uso direto humano, ou seja, não admitem a presença humana como habitantes permanentes. Essa mesma lógica tem sido utilizada em nível estadual, pois os parques estaduais adotam os mesmos tipos de restrição dos parques nacionais, por exemplo. 
Apesar da proibição da permanência de moradores locais, mesmo daqueles que se estabeleceram antes da implantação da UC, PARNAS estimulam prioritariamente o desenvolvimento do ecoturismo, da educação ambiental e da pesquisa científica. Como era de se esperar, é no interior e no entorno de UCs de uso indireto que ocorrem a maior parte dos conflitos entre pessoas e unidades de conservação da natureza. As reservas biológicas merecem destaque, porque adotam uma política ainda mais rigorosa. Nessa categoria de UC, nenhum tipo de atividade humana é permitida, com exceção de pesquisas científicas oficialmente autorizadas e previstas no plano de manejo da UC em questão.

A segunda razão para sugerirmos que o impacto social indireto (sobre as pessoas que permanecem nas UCs) seja maior do que o impacto direto causado por expulsões e desapropriações, é que, apesar de também não existirem dados quantitativos oficiais, a literatura e nossa experiência sugerem que a maior parte dos moradores residentes em UCs de proteção integral ainda não foi removida por causa da complexidade jurídico-legal e histórica das questões fundiárias no Brasil, a não realização da reforma agrária prometida pelos governos de "esquerda", pela falta de vontade política refletida na morosidade do aparato governamental, pela falta de recursos financeiros e recursos humanos para conduzirem as desapropriações, e o papel das forças econômicas e poderes políticos locais que podem tanto impedir como acelerar a criação dessas áreas. Conforme será discutido nesse artigo, o fato é que esses tipos de remoções ferem diretamente o que foi assegurado na constituição federal de 1988, assim como na Convenção 169 da OIT, da qual o Brasil é signatário.

Entendemos que o impacto da criação de UCs de proteção integral seja significativo - não apenas sobre aquelas pessoas que são removidas, mas também sobre os que permanecem, pois experimentam mudanças socioeconômicas, culturais e ambientais substantivas, apesar de pouco conhecidas, discutidas e enfrentadas nos meios acadêmicos do campo ambiental e do direito. É possível até, em alguns casos, que a permanência de comunidades, famílias e indivíduos em uma área de proteção integral possa causar mais danos do que a remoção em si, mesmo com a devida indenização. Ao permanecerem, essas pessoas geralmente são criminalizadas pelas políticas ambientais, 
percebidas como 'degradadoras' da natureza, quando muitas vezes, historicamente atuaram como guardiões do ambiente hoje alvo da conservação em unidades de conservação. Nesses lugares, essas pessoas forjaram sentidos e transmitiram técnicas de cuidado com a natureza, a partir de saberes tradicionais que contribuíram decisivamente na conservação do lugar-alvo central de políticas de conservação em UCs. Sob tais condições, essas pessoas encontram uma série de barreiras à reprodução de suas culturas e hábitos de manejo ambiental. Por exemplo, a proibição de fazer agricultura, de criar animais ou mesmo de coletar produtos florestais não-madeireiros, tais como plantas medicinais. O efeito concreto e material, assim como a reprodução da subalternidade - a perda de liberdade, por meio da vigilância e do controle exercido pelo aparato de monitoramento ambiental, exerce forte pressão emocional na qualidade de vida das populações residentes de UCS de proteção integral. É como se essas populações fossem as menos importantes, e, portanto, deixadas propositalmente em uma situação de tamanha dificuldade, que a única, ou a melhor opção, fosse abandonar a área por "livre e espontânea vontade". Em outras palavras, a aplicação da legislação ambiental muitas vezes pode resultar em condições de opressão extrema para as comunidades tradicionais, sendo que a única alternativa nesse contexto é a saída do território.

Pesquisas etnográficas conduzidas pelo autor desse artigo indicam que a criação de obstáculos para a chagada da luz, ou melhor, do acesso à energia elétrica para comunidades rurais e tradicionais tem sido tática comum utilizada em UCs de proteção integral, que buscam impedir ou limitar certos tipos de desenvolvimento considerados incompatíveis com os objetivos de sustentabilidade e, mais especificamente, da conservação da natureza. Por exemplo, no núcleo Picinguaba (Ubatuba, SP), do parque estadual da serra do mar (PESM), a luz só chegou na comunidade de estudo em 2007, após anos de protestos e manifestações organizadas pelas próprias populações locais, sendo impulsionada, principalmente, pelo reconhecimento em 2003 dessa comunidade como um quilombo, processo esse, conduzido por agentes da Fundação Instituto de Terras de São Paulo (ITESP) (PENNA-FIRME, BRONDÍZIO, 2013).

Outra questão fundamental, altamente negligenciada no Brasil, é que impactos negativos sobre comunidades locais residentes de UCs podem aumentar a pobreza 
humana em hotspots de biodiversidade, de modo que a conservação ambiental pode coexistir com a injustiça social (STONICH, 1993). Temos argumentado que sob certas circunstâncias, a criação de UCs, principalmente as de proteção integral, em territórios ocupados por comunidades tradicionais, ou historicamente habitados por pobres rurais, tende a levar esses grupos a viverem em um estado limitado de oportunidades de desenvolvimento socioeconômico (PENNA-FIRME, BRONDíZIO, 2007).

O processo de neoliberalização das relações cultura-natureza em UCs ocorre, em grande medida, por meio do que denominamos mais valia socioambiental. Definimos o termo com sendo o total das funções, provisões ou serviços não suficientemente compensados, que são prestados por pessoas e comunidades locais em coparticipação com a natureza, por meio do trabalho de produção de conhecimentos locais sobre o uso, o manejo e a conservação da natureza. O déficit, ou os benefícios não recompensados ou pagos, são produzidos pela redução de oportunidades de desenvolvimento, notadamente pela proibição ou restrição de certos tipos de trabalho considerados antiecológicos ou insustentáveis ambientalmente. Ou seja, as pessoas (co)produtoras desses "serviços" junto com a natureza devem, por vontade própria e/ou coerção, abrir mão de certos caminhos de desenvolvimento para benefício de uma causa ecológica, que se impõe a toda humanidade, não apenas por necessidade, mas principalmente pela crescente hegemonia do discurso da sustentabilidade global.

A situação descrita acima, muito se assemelha ao problema central do protocolo de Kyoto, assinado por diversos países em 1998. Em síntese, os países do norte desenvolvido e os do Sul em desenvolvimento travaram uma batalha moral épica para tentar definir o que seria justo e viável para uma ação global de redução dos gases do efeito estufa na atmosfera. A questão central que nos interessa aqui é que países em desenvolvimento, como o Brasil e Índia, argumentaram que não poderiam se comprometer com as metas de redução de gases da mesma maneira que os países desenvolvidos, como Estados Unidos e Japão, uma vez que historicamente haviam emitido quantidades muito menores de $\mathrm{CO}^{2}$ e outros gases estufa para a atmosfera. Argumentavam que cumprir as mesmas metas, significava tirar-lhes o direito de seguir caminhos de desenvolvimento similares, ou seja, com base em uma matriz energética 
petrolífera, o que foi crucial para que países como os Estados Unidos atingissem o nível de sofisticação e desenvolvimento tecnológico que possuem hoje. Nesse contexto, surgiram propostas que deram origem ao que hoje conhecemos como mercados de carbono. Ou seja, o Brasil, por exemplo, propôs que deveria receber créditos de carbono por manter as florestas em pé, o que sacrificaria outras formas de desenvolvimento e lucro, como a expansão da agropecuária e a própria exploração de madeiras tropicais.

De forma similar, querer que moradores tradicionais e locais de hotspots de biodiversidade limitem seus desejos e necessidades de consumo e desenvolvimento tecnológico (como o simples direito de ter luz em suas moradias, ou possuir uma oficina de reparo de motocicletas ao invés de uma rede de pesca) é querer que essas pessoas paguem o preço da conservação global, sem, no entanto, serem adequadamente compensados por isso. Dessa maneira, centenas de moradores de UCS no Brasil e no mundo têm sido forçados a permanecer cristalizados em um estado idílico, romântico, e imaginados de tradicionalidade para benefício da conservação e do turismo.

\section{Carvoeiros do passado e agricultores do presente: buscando elos históricos}

\section{no parque estadual da Pedra Branca}

Dentro dos limites do PESPB já foram identificados e mapeados mais de 1000 vestígios de carvoarias e aproximadamente 50 ruínas de antigas moradias em meio à densa floresta de Mata Atlântica (OLIVEIRA, FRAGA, 2011). Essas carvoarias e ruínas foram feitas no final do século XIX e início do século XX. No entanto, o que mais chama a atenção, pelo menos para a finalidade da presente análise, é que essas marcas humanas na paisagem foram quase que, indubitavelmente, deixadas por ex-escravos libertos, alforriados e fugitivos: trabalhadores invisíveis (OLIVEIRA, FRAGA, 2011, op. cit.).

Oliveira e colaboradores têm demonstrado amplamente que não há historiografia (registro oficial escrito) sobre os carvoeiros da cidade do Rio de Janeiro. O que existem são marcas deixadas na paisagem, notadamente percebidas pela análise fitossociologia (composição e estruturas) de espécies arbóreas da Mata Atlântica nas áreas manejadas para produção de carvão, e pela presença de ruínas de casas, conforme já mencionamos. 
Além dessas marcas, existem indícios da existência de muitas áreas utilizadas para roças de subsistência desses trabalhadores invisíveis.

Segundo os autores acima, muito possivelmente a fabricação de carvão era um trabalho para escravos alforriados ou pequenos agricultores e não parte integrante do sistema produtivo dos engenhos. A fabricação do carvão era uma atividade que permitia uma relativa independência, já que a quantidade de insumos utilizada na produção de carvão era mínima. Um machado, um enxadão, um ancinho e um isqueiro eram tudo o que se precisava para a sua produção. Apesar do intenso processo de invisibilização social a que os carvoeiros estavam sujeitos, somente no Maciço da Pedra Branca eles foram responsáveis pela exploração de uma área de mais de 10.000 hectares. Hoje, transformado em um Parque Estadual, sua floresta atlântica tem a sua estrutura e composição florística em grande parte determinada por esta atividade do passado. As implicações ecológicas da exploração da lenha para a produção de carvão não resultaram em efeitos ecológicos negativos expressivos. Estas 1.000 carvoarias inventariadas devem ter produzido mais de 13.000 toneladas de carvão para uma cidade que tinha nestes recursos sua principal matriz energética. No entanto, apesar do intenso desmatamento no final do século XIX, a floresta retomou graças à sucessão ecológica, constituindo hoje o Parque Estadual da Pedra Branca. Apesar do desmatamento, a sustentabilidade ecológica do período de fabricação do carvão foi um fato concreto. Afinal a retomada da floresta nesta área de exploração permitiu, cerca de 70 anos depois, a criação de uma significativa Unidade de Conservação. Mas, e a sustentabilidade social dessa atividade? São pouquíssimas as informações disponíveis sobre estes atores sociais, que forneciam energia à cidade do Rio de Janeiro. Os carvoeiros em muito pouco se beneficiaram do seu trabalho, enquanto que muitos lucraram com ele. São até hoje invisibilizados do ponto de vista social e ignorados pela historiografia oficial. Dessa história, o único documento que nos restou foi o seu território, hoje transformado em belo parque, que esconde, em meio a uma densa floresta, uma história de esquecimentos e desigualdades entre as pessoas que nela viveram e que dela se utilizaram.

Atualmente, tanto as áreas de produção de carvão como as áreas de roça estão totalmente cobertas por densa vegetação de Mata Atlântica, o que atesta para a 
existência de práticas de manejo sustentáveis do ponto de vista ecológico, uma vez que após seu abandono, permitiu o retorno e manutenção de boa parte da biodiversidade original, assim como do funcionamento ecológico da paisagem. A presença da floresta hoje, desconsiderada sua história ambiental, nos parece um dado da natureza, ou seja, algo que sempre existiu de forma intocada pelas mãos humanas. Essa mentalidade tem ganhado força com a difusão de discursos conservacionistas de orientação biocêntrica. No caso em questão, pode-se dizer que a implantação do PESPB - sem levar em consideração a presença humana histórica nessa paisagem, é o ápice de um longo processo de mercantilização da natureza que vem apagando as histórias de vida locais, as lutas, os amores, os medos e os sonhos dos primeiros moradores e seus descendentes atuais. Também é um processo de substituição de cosmologias e de direitos. Antes a floresta era a casa, a moradia, a dignidade, o sustento, o refúgio e o trabalho, hoje ela vem se tornando o território do turismo, o cartão postal da população urbana e uma espécie de parque de diversão dos cientistas naturais.

Antigos caminhos utilizados por moradores locais hoje são trilhas ecológicas para turistas. Esses caminhos estão repletos de histórias e significados hoje esquecidos; pois eram locais por onde passavam mercadorias e produtos da floresta e da cidade, trazidos no lombo de mulas, assim como pelas próprias pessoas, que entendemos como donos legítimos desses territórios. Tais espaços eram fundamentais na manutenção dos laços de família entre parentes que habitavam casas distantes, assim como serviam de ligação entre o trabalho na roça, a floresta e o mundo exterior (RODRÍGUEZ CÁCERES, 2016). Entendemos que a transformação de antigos caminhos em trilhas ecológicas a serem consumidas pelos caminhantes do parque seja uma forma sutil de mercantilização da natureza.

Observados em conjunto, os resultados das pesquisas em história ambiental sobre as carvoarias e algumas evidências antropológicas que iremos relatar a seguir, sugerem que muitos dos agricultores que permanecem dentro dos limites do PESPB sejam descendentes dos carvoeiros que fizeram moradia nas áreas do maciço. Cabe ressaltar que apesar da história de uso e ocupação dessa região e da presença de descendentes de Africanos escravizados, a maioria dos que vivem atualmente nos limites do parque não se 
auto identificam nem como descendentes de carvoeiros nem como quilombolas. Como relatado por FERNANDEZ (2011), a força do processo de invisibilização social, ou a visibilidade negada, tem sido tão poderosa e hegemônica que os habitantes dessas terras tradicionalmente ocupadas ainda se identificam quase que exclusivamente como agricultores familiares. Nesse sentido, até o presente momento, não parece haver consciência plena de sua herança, e conhecimento e articulação suficientes dessas pessoas para que acionem o direito de reconhecimento quilombola.

No caso da ligação entre os carvoeiros e os agricultores da Pedra Branca, os relatos que estão sendo coletados dos agricultores (ainda em andamento) sobre relações de parentesco e uso pretérito do território estão sendo confirmados pelos resultados apresentados até agora pelas abordagens da história ambiental. Em outras palavras, as marcas deixadas na paisagem pelos carvoeiros, assim como os vestígios de residências e as centenas de carvoarias abandonadas servem, de fato, como preconiza a história ambiental, de documento sobre o passado não registrado nos livros e cartórios.

No primeiro semestre do ano de 2014, o autor desse artigo participou de um trabalho de campo exploratório com a finalidade de dar início à observação direta e coleta de relatos sobre os usos pretéritos daquele território, hoje transformado em UC. Já nesse primeiro momento, a equipe de campo deparou-se com uma situação bastante reveladora. Aqui trazemos parte dessas observações e do relato, ainda que preliminar, de um dos moradores locais já identificados como descendente de carvoeiro.

Aproximadamente duas horas de caminhada morro acima, no meio da floresta, encontramos o senhor João (pseudônimo para preservar sua identidade), um morador de aproximadamente 50-60 anos, já conhecido por membros da nossa equipe. "Seu” João um homem pobre e negro, de aparência franzina, que havia nascido e sido criado em uma pequena casa dentro dos limites do parque, nos contou espontaneamente histórias bastante reveladoras. Reproduzimos a seguir, com nossas palavras, uma síntese dos relatos que ele nos forneceu.

Ao ser questionado sobre seu conhecimento sobre carvoarias, João deu uma aula de conhecimento local sobre como fazer uma carvoaria, também nos contando que seu 
avô era exímio carvoeiro, e que ele mesmo, quando criança, testemunhou seu avô fazendo uma das últimas carvoarias da região. É preciso destacar que pela descrição, aparentemente, essa carvoaria seguia a mesma técnica daquelas centenas mapeadas sob as encostas declivosas do maciço da Pedra Branca. O conhecimento aprofundado desse informante sobre carvoarias, assim como a relação explícita de parentesco dele com um dos prováveis últimos carvoeiros ativos nos chamou a atenção.

A partir desse encontro com Seu João, passamos a construir a perspectiva que apresentamos aqui sobre as relações entre os carvoeiros do passado, os agricultores do presente e os turistas do futuro. O quadro maior de entendimento dos acontecimentos do passado, revelado pela leitura da paisagem, e das circunstâncias do presente observadas diretamente, começava a fazer mais sentido. Em outras palavras, caso fosse comprovado que ao menos parte dos moradores e agricultores atuais fosse, como "Seu" João, um descendente direto de carvoeiros, poderíamos de alguma forma supor que todo ou quase todo território e seus habitantes, atualmente confiscado para a proteção da natureza e promoção do ecoturismo, seria um patrimônio cultural, uma herança coletiva coproduzida pelo trabalho dos carvoeiros e de seus descendentes, que dentro de certos limites foram moldados e moldaram o que hoje chamamos de natureza. Conforme veremos na seção seguinte, todo vestígio de trabalho em carvoarias, assim como os modos de vida atuais dos seus descendentes pode ser alvo de proteção jurídica, dentro do conceito de patrimônio cultural. Do mesmo modo, todo território quilombola é um patrimônio afro-brasileiro a ser resguardado pela Constituição Federal.

Uma hipótese, talvez radical, mas não menos plausível, seria entendermos que as marcas deixadas na paisagem pelos carvoeiros representem um conjunto de evidências materiais para que num futuro próximo, agricultores da Pedra Branca, reivindiquem parte do que hoje virou parque como um quilombo - possivelmente, esse corresponderia a maior extensão de terras identificada como quilombo no sudeste brasileiro, também no bioma da Mata Atlântica. No entanto, cabe ressaltar que um eventual reconhecimento de um remanescente de quilombo dentro dos limites do PESPB não seria o primeiro caso reportado de sobreposição entre UCs de proteção integral e territórios tradicionalmente ocupados. É importante termos em mente que apesar da ocupação histórica de 
“descendentes de carvoeiros" nessas cercanias, conforme dito anteriormente, essas pessoas ainda não se reconhecem como quilombolas. Soma-se a isso o fato de que tal categoria de sujeitos coletivos (descendente de carvoeiro), ainda não se constitui em grupo étnico ou comunidade tradicional, ao menos, do ponto de vista da legislação vigente, dos grupos que reivindicam o que estabelece a política nacional de povos e comunidades tradicionais. Algumas dessas terras tradicionalmente ocupadas são auto identificados como: terras de quilombos, terras indígenas, "babaçuais livres, "castanhais do povo", faixinais e fundos de pasto (ALMEIDA, 2008).

Conforme critica Fernandez (2011), passadas três décadas da criação do PESPB, para os agricultores locais, não se trata mais de questionar a existência do Parque, mas de afirmar a possibilidade de nele permanecer a partir do reconhecimento jurídico-formal de suas formas de ocupação específicas e uso dos recursos naturais. Poderíamos dizer que "o carro está passando na frente dos bois", a saber, a história e cultura dos agricultores que ainda resistem pode se perder em função da imposição do capitalismo verde.

Território para ecoturistas, patrimonialização cultural, efetivação de posse de terras ou reconhecimento étnico/territorial? Eis a questão

Ainda que tardiamente, a legislação brasileira tem reconhecido direitos das populações tradicionais, assim como a necessidade de identificar e proteger o patrimônio cultural produzido pelos mais diversos grupos sociais minoritários. A Constituição de 1988 reconhece direitos originários, recentemente ampliados pelo Decreto 6.040/07, que cria a Política Nacional dos Povos e Comunidades Tradicionais. De acordo com o decreto:

São grupos culturalmente diferenciados e que se reconhecem como tais, que possuem formas próprias de organização social, que ocupam e usam territórios e recursos naturais como condição para sua reprodução cultural, social, religiosa, ancestral e econômica, utilizando conhecimentos, inovações e práticas gerados e transmitidos pela tradição.

A inovação legal previu, explicitamente, o direito ao território das comunidades tradicionais aos remanescentes das comunidades dos quilombos mediante 0 
reconhecimento da propriedade definitiva. Quanto aos povos indígenas, a constituição reconheceu a organização social, costumes, línguas, crenças e tradições, e os direitos originários sobre as terras ocupadas pelos mesmos.

Pela análise dos documentos jurídicos anteriores a Constituição de 1988 é possível dizer que, até então, a preocupação legislativa recaía tão somente sobre o extermínio e integração dos índios (BELFORT, 2006), e, quanto aos quilombolas e demais populações tradicionais, a normativa desconsiderava a necessidade de previsão de direitos diferenciados, tendo a segregação como via de consequência. Imaginar a garantia do direito de propriedade a essas populações antes de 1988 significava romper com a normativa que, via de regra, era de privilégios a propriedade privada em detrimento do interesse e direitos coletivos.

Além da previsão específica quanto ao direito dos quilombolas e índios, a Constituição Federal de 1988, em seus artigos 215 e 216, garantiu a todos o pleno exercício dos direitos culturais e acesso às fontes da cultura nacional, e, para tanto, definiu que integram o patrimônio cultural os bens de natureza material e imaterial (tangíveis e intangíveis), tomados individualmente ou em conjunto, portadores de referência à identidade, à ação e à memória dos diferentes grupos formadores da sociedade brasileira, incluídos as formas de expressão e os modos de criar, fazer e viver. Também, a Política Nacional de Desenvolvimento Sustentável dos Povos e Comunidades Tradicionais de 2007 definiu territórios tradicionais como sendo "os espaços necessários a reprodução cultural, social e econômica dos povos e comunidades tradicionais, sejam eles utilizados de forma permanente ou temporária, observado, no que diz respeito aos povos indígenas e quilombolas, respectivamente, o que dispõem os arts. 231 da Constituição e 68 do Ato das disposições transitórias e demais regulamentações".

Há que se compreender que patrimônio, originalmente definido como "herança paterna" ou "herança comum", no sentido jurídico entende-se como o conjunto de bens, direitos e obrigações pertencente a uma pessoa jurídica ou natural, constituindo uma universalidade. Patrimônio cultural pode ser definido como o conjunto de bens transmitidos a uma geração seguinte (herança comum), onde se insere o trabalho, a 
criatividade, a espiritualidade, as crenças, o cotidiano, e todo o extraordinário das gerações anteriores (MACHADO, 2014).

A mesma Carta Magna garantiu a todos, sem distinção, em seu artigo 2250 “direito ao meio ambiente ecologicamente equilibrado, bem de uso comum do povo e essencial à sadia qualidade de vida, impondo-se ao Poder Público e à coletividade o dever de defendê-lo e preservá-lo para as presentes e futuras gerações. " Na forma constitucional, também integram o meio ambiente os bens de natureza material ou imaterial, criados pelo ser humano, que podem ser tomados individual ou coletivamente, os quais fazem referência à identidade, à ação, à memória dos diferentes grupos formadores da sociedade brasileira.

Não existem dúvidas de que a criação de Unidades de Conservação como política pública para preservação dos recursos naturais é de suma importância para fins de cumprimento da vontade legislativa expressa no artigo citado. Da mesma maneira, atribuindo uma interpretação integrada aos dispositivos Constitucionais, tem-se que a finalidade da criação de tais Unidades de Conservação, deveria, indubitavelmente, ter como objeto de proteção não somente do que se chama natureza, mas também, e principalmente, o patrimônio cultural, já que, no viés da Lei Maior brasileira, impossível conceber proteção ao meio ambiente sem incluir o ser humano e suas atividades culturais e materiais.

Como já dito aqui, a análise da história de criação dos parques no Brasil, sejam os criados pela União, ou Estados e Municípios, demonstra que a natureza tem sido o único, ou principal, bem jurídico que se busca proteger, em contraponto a desarticulação e destruição do patrimônio cultural, como especificamente vem acontecendo aos descendentes de carvoeiros do PESPB, cuja história, e, sobretudo, sua herança, consubstanciada no patrimônio cultural, bem imaterial, tem sido rigorosamente suplantado em prol do desenvolvimento do capitalismo verde.

Essa problemática tem sido objeto de análise e julgamento nos tribunais brasileiros, de modo que o Superior Tribunal de Justiça tem marcado posição de que a herança coletiva e intergeracional do patrimônio ancestral, mesmo quando não se revele 
em luxo, glamour e suntuosidade, deve ser objeto de proteção do Estado. Abaixo transcrevemos trecho de um julgamento do referido tribunal (BRASIL, 2011), de relatoria do Ministro Herman Benjamin:

Por meio de tombamento ou de outras formas de intervenção administrativa e judicial, a atuação do Estado não protege - nem deve proteger ou muito menos exaltar - apenas estética refinada, arquitetura suntuosa, produção artística luxuosa, templos esplendorosos, obras grandiosas dedicadas ao ócio, ou sítios comemorativos de façanhas heroicas dos que instigaram ou lutaram em guerras, com elas ganharam fama ou enriqueceram. Além de reis, senhores e ditadores, a História vem contada também pelos feitos, revoltas e sofrimentos dos trabalhadores, dos pobres, dos estigmatizados e dos artífices mais humildes da Paz. Para que deles, do seu exemplo, coragem e adversidade nunca se olvidem as gerações futuras, fazem jus igualmente à preservação seus monumentos, conjuntos e locais de interesse, com suas peculiares marcas arquitetônicas, mesmo que modestas e carentes de ostentação, assim como seus rituais, manifestações culturais, raízes etnológicas ou antropológicas, e até espaços de indignidade e desumanidade - do calabouço à senzala, da sala de tortura ao campo de concentração. Tal qual quando socorre as promessas do futuro, o ordenamento jurídico brasileiro a ninguém atribui, menos ainda para satisfazer interesse individual ou econômico imediatista, o direito de, por ação ou omissão, destruir, inviabilizar, danificar, alterar ou comprometer a herança coletiva e intergeracional do patrimônio ancestral, seja ele tombado ou não, monumental ou não.

Podemos compreender que a história e a herança deixada pelos carvoeiros do passado não interessam somente aos agricultores do presente, mas deve ser objeto de proteção e valoração do Estado, como forma de garantir às gerações presentes e futuras o conhecimento, acesso a história e preservação do patrimônio e legado de um grupo, que como todos, merece ser objeto de reconhecimento e valorização.

No caso em análise nesse artigo há uma evidente colisão de direitos fundamentais constitucionalmente garantidos, bem como de ações estatais que emanam do dever legal, e que devem, urgentemente, serem colocados na balança. De um lado a pretensa preservação da natureza, e de outro, o direito a preservação do patrimônio cultural dos agricultores, consistente na forma de trabalho, na criatividade, na espiritualidade, crenças, cotidiano, e todo o extraordinário modo de viver das gerações antepassadas. Não há, de fato, uma hierarquia entre tais direitos, mas certo é que o tempo deve ser a 
medida da urgência, pois estamos diante da possível perda de uma herança coletiva, construída por séculos de árduo trabalho de atores invisíveis que, pelas pesquisas já citadas, foram fundamentais para o sustento e desenvolvimento da própria sociedade que hoje não os reconhece.

Uma série de questões, ainda sem resposta, precisa ser enfrentada por abordagens interdisciplinares que envolvam teorias, métodos e interpretações da história ambiental, em conjunto com a antropologia, a ecologia política e o direito. Contudo, mesmo sem dispor das mesmas, não nos furtamos às seguintes questões: Qual direito deve prevalecer, o da preservação ou da conservação do patrimônio cultural coletivo? Quem tem direito de contar a história, os conservacionistas, os turistas ou os moradores locais, uma vez que são comunidades tradicionais que tem direitos garantidos? Como garantir a intocabilidade do patrimônio histórico cultural ali existente? Num conflito dessa natureza qual direito deve prevalecer? Qual bem jurídico é mais relevante ou valioso? Quem decide o que é mais valioso? Perguntas dessa natureza precisam ser respondidas não apenas por juristas e legisladores, mas sobretudo, por atores diretamente envolvidos com a gestão e execução das políticas ambientais. É preciso que haja uma ampliação de conhecimento e diálogo entre tomadores de decisão, gestores, pesquisadores das ciências naturais e sociais em busca de obtermos mais avanços concretos no reconhecimento de direitos assegurados nesse e em outros contextos.

\section{Considerações finais}

Nesse artigo buscamos identificar e estabelecer prováveis conectividades históricas entre antigos carvoeiros e atuais agricultores familiares que ocupam um território transformado em uma UC de proteção integral. Evidências indicam que um percentual considerável desses agricultores que hoje habitam e geram parte da sua renda dentro dos limites do parque sejam descendentes diretos de carvoeiros do século XIX e XX. A reconstrução dessas conexões, ainda que em andamento, levanta uma série de indagações sobre as relações sociedade-natureza, notadamente, sobre formas de 
assegurar os direitos fundamentais e garantias constitucionais, consubstanciados no direito à preservação do patrimônio cultural dos carvoeiros, integrando sua forma de trabalho, criatividade, espiritualidade, crenças, cotidiano, e todos os direitos que possam advir desse patrimônio. Argumentamos que populações residentes antes da criação da UC e seus descendentes são parte do patrimônio cultural em si mesmas.

Por fim, argumentamos que a criação do PESPB, assim como iniciativas similares pelo mundo todo, tem sido sobremaneira desacompanhada de uma preocupação com os impactos negativos diretos e indiretos que esse modelo impõe aos modos de vida locais. Sobretudo, entendemos que a história e a identidade cultural desses grupos têm sido desprezadas, consequentemente, direitos fundamentais têm sido violados em nome de uma sustentabilidade ambiental que produz e é produto de desigualdades socioeconômicas mais amplas. Defendemos a ideia de direitos preexistentes, o que é corroborado por evidências históricas (marcas na paisagem), da presença humana anterior ao parque.

Sugerimos a ampliação de estudos histórico-antropológicos no PESPB no intuito de dar maior visibilidade (e criar alternativas) às condições materiais e socioculturais de agricultores familiares e descendentes de carvoeiros, face à lógica que vem paulatinamente transformando paisagens culturais centenárias em mercadorias. Por meio da transformação de espaços que outrora se caracterizavam por refletirem e incorporarem múltiplos usos vêm sendo implantados distintos valores e significados culturais em territórios voltados, quase que exclusivamente, para visitação turística, preservação da biodiversidade e de manutenção de "serviços" ecossistêmicos.

Acreditamos que reflexões dessa natureza possam contribuir na mudança de percepção e orientação de políticas públicas que busquem, de fato, uma melhor compatibilização entre objetivos de conservação da natureza, de combate à pobreza e do desenvolvimento humano como um todo, bem como que sejam capazes de dirimir os conflitos dos direitos fundamentais constitucionalmente previstos. 


\section{Referências}

ACSELRAD. Henri. Ambientalização das lutas sociais: o caso do movimento por justiça ambiental. Estudos Avançados, v.24, n.68, 2010.

ALMEIDA, Alfredo. W. B. Terras de quilombos, terras indígenas, "babaçuais livres, "castanhais do povo", faixinais e fundos de pasto: terras tradicionalmente ocupadas. 2. Ed. Manaus: PGSCA-UFAM, 2008.

ALMEIDA, Alfredo. W. B. Territórios e territorialidades específicas na Amazônia: entre a “proteção" e o "protecionismo". Caderno CRH Salvador, v. 25, n. 64, p. 63-71, Jan./abr. 2012.

BELFORT, Lúcia. F. I. A proteção dos conhecimentos tradicionais dos povos indígenas, em face da convenção sobre diversidade biológica. 2006. 139 f. Dissertação (Mestrado em Direito) - Universidade de Brasília, Faculdade de Direito, Brasília, 2006.

BRASIL. Constituição (1988): Art. 68 do Ato das Disposições Constitucionais Transitórias da Constituição da República Federativa do Brasil: promulgada em 5 de outubro de 1988. Disponível em:

<http://www.senado.gov.br/atividade/const/con1988/ADC1988_12.07.2016/art_68_.asp.> Acesso em 05 de outubro. 2017.

BRASIL. Decreto $\mathrm{n}^{\circ}$ 6.040, de fevereiro de 2007: institui a Política Nacional de Desenvolvimento Sustentável dos Povos e Comunidades Tradicionais.200, 2007. Disponível em <http://www.planalto.gov.br/ccivil_03/_at02007-

2010/2007/decreto/d6040.htm>. Acesso em 05 de outubro. 2017.

BRASIL. Superior Tribunal de Justiça . Recurso especial nº 1.293.608 - PE (2011/0101319-3), Relator Ministro Herman Benjamin, 2011. Disponível em <https://www.jusbrasil.com.br/diarios/documentos/138715402/recurso-especial-n1293608-pe-do-stj $>$. Acesso em 05 de outubro. 2017.

BROCKINGTON, Dan; DUFFY, Roseleen.; IGOE, James. Nature Unbound: conservation, capitalism and the future of protected areas. 1. ed. London and Washington DC: Earthscan, 2010.

CUNHA, Manoela CARNEIRO DA. Cultura com aspas. São Paulo: Cosac Naify, 2009.

ESCOBAR, Arturo; PAULSON, Susan. The emergency of collective ethnic identities and alternative political ecologies in the Colombian Pacific Rainforest. In: PAULSON, Susan; GEZON, Lisa (Org.). Political Ecology across space, scales, and social groups. 1. ed. New Jersey: Rutgers University Press, 2005. p. 55-78. 
FAIRHEAD, James; LEACH, Melisa.; SCOONES, Ian. Green grabbing: a new appropriation of nature: London and New York: Routledge, 2013.

FERNANDEZ, Annelise C. F. Um Rio de florestas: uma reflexão sobre o sentido da criação dos parques na cidade do Rio de Janeiro. Est. Hist., Rio de Janeiro, v. 24, n. 47, p. 141-161. 2011.

FLETCHER, Robert; DRESSLER, Wolfram; BUSCHER, Bram. The new frontiers of environmental conservation. In: BUSCHER, B. (Org.). Nature TM Inc. Arizona. Tucson, AZ: The University of Arizona Press, 2014. p. 65-98.

HACOHEN, Malachi. H. Karl Popper: the formative years, 1902-1945: politics and philosophy in interwar Vienna. [S. I.]: Cambridge University Press, 2000.

INSTITUTO CHICO MENDES DE CONSERVAÇÃO DA BIODIVERSIDADE. Unidades de Conservação. 2016. Disponível em: <www.icmbio.gov.br>. Acesso em 11 out. 2016.

JENKINS, Tiffany. Contesting Human Remains in Museum Collections: the crisis of cultural authority. New York, NY: Routledge, 2010.

MACHADO, Paulo A. L. Direito Ambiental Brasileiro. São Paulo: Malheiros Editores, 2014.

OFTEN, Karl. The territorial Black Turn: Making black territories in Pacific Colombia. Journal of Latin American Geography. Texas, v.2, n.1. p, 43-73, 2003.

OLIVEIRA, Rogério; FRAGA, Joana. Metabolismo social de uma floresta e de uma cidade: paisagem, carvoeiros e invisibilidade social no Rio de Janeiro dos séculos XIX e XX. GeoPUC, ano 4, n. 7. 2011.

OLIVERA, Oscar. Cochabamba! Water War in Bolivia. New York, NY: South end Press, 2004 .

OSTROM, Elinor. A Diagnostic Approach for Going beyond Panaceas. Proceedings of the National Academies of Science of the United States of America. v. 104, n.39,:p.15181$15187,2007$.

PENNA-FIRME, Rodrigo; BRONDÍZIO, Eduardo. Quilombolas como "coletividades verdes": contestando e incorporando o ambientalismo na Mata Atlântica, Brasil.

Ambiente e Sociedade, v.20, n.2, p.141-162, 2017.

PENNA-FIRME, Rodrigo; BRONDÍZIO, Eduardo. The risks of commodifying poverty: rural communities, quilombola identity, and nature conservation in Brazil. Habitus, v. 5, n. 2, p. 355-373, 2007. 
PORTO-GONÇALVES, Carlos.W. A globalização da natureza e a natureza da globalização. 1. ed. Rio de Janeiro: Civilização Brasileira, 2006.

RODRÍGUEZ CÁCERES, Luz S. Do caminho à trilha: as perspectivas do lazer e do habitar na Transcarioca. Interseções, v.18, n.11, p.64-96, 2016.

STONICH, Susan. I am destroying the land: the political ecology of poverty and environmental destruction in Honduras. 1. Ed. Boulder, CO: Westview Press, 1993.

ZHOURI, Andréa. Justiça ambiental, diversidade cultural e accountability: desafios para a governança ambiental. Revista Brasileira de Ciências Sociais, v. 23, n. 68, 2008.

ZIZEK, Slavoj. Ecology: a new opium for the masses. 2016. Disponível em: <http://www.nextnature.net/2009/02/ecology-a-new-opium-for-the-masses/>. Acesso em 11 out. 2016. 